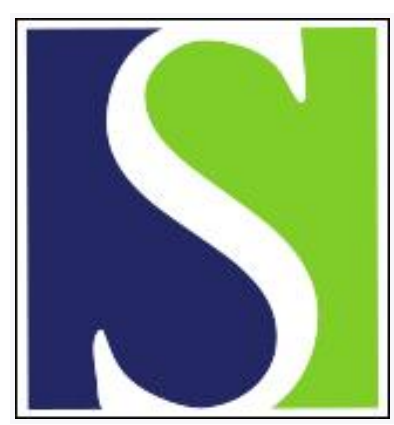

Scand J Work Environ Health 1987;13(4):330-333

https://doi.org/10.5271/sjweh.2032

Issue date: Aug 1987

Esthesiometry, nail compression and other function tests used in Japan for evaluating the hand-arm vibration syndrome.

by Harada $\mathrm{N}$

Affiliation: Department of Public Health, Ehime University School of Medicine, Japan.

This article in PubMed: www.ncbi.nlm.nih.gov/pubmed/3433034 


\title{
Esthesiometry, nail compression and other function tests used in Japan for evaluating the hand-arm vibration syndrome
}

\author{
by Noriaki Harada, MD ${ }^{1}$
}

\begin{abstract}
HARADA N. Esthesiometry, nail compression and other function tests used in Japan for evaluating the hand-arm vibration syndrome. Scand $J$ Work Environ Health 13 (1987) 330-333. Various function tests are performed on the upper extremities of patients in Japan as part of a systematic method for diagnosing the hand-arm vibration syndrome. Although the observations are not confined to the hands and arms, but include the whole body, the evaluation of the syndrome is essentially based on the severity of Raynaud's phenomenon and the findings of the function tests. With the function tests, including a cold provocation test with $10^{\circ} \mathrm{C}$ water, the efficiency of discrimination between workers with vibration-induced white finger and reference workers was investigated. The results indicated that the function tests were of diagnostic significance for the hand-arm vibration syndrome. The influences of ageing, atmospheric temperature in the test room, seasonal variation in temperature, and reproducibility were investigated to clarify some points. The equipment and techniques have been basically standardized. However, for comparing and analyzing the results of the function tests performed in different research institutes, further investigation of the standardization of the test and evaluation methods is necessary.
\end{abstract}

Key terms: ageing effect, clinical features, cold provocation test, diagnostic significance, function test, reproducibility, seasonal variation, sensitivity, specificity, standardization.

For the diagnosis of the hand-arm vibration syndrome in Japan, various function tests are widely performed on the upper extremities. These function tests were developed for the purpose of assessing the functional disorders of the hand-arm system in the early stage. A number of researchers has contributed to the development of these tests, which were nearly completed in the early 1970 s, especially after comprehensive surveys of the syndrome were started in the national forests and the forests under private ownership (15). The Japanese Ministry of Labour accepted the function tests as criteria for compensation in 1975 (10). Further investigations into the diagnostic significance of these tests are still in progress.

\section{The function tests}

The function tests comprise peripheral circulatory and sensory tests, including cold provocation and motor tests of functional capacity in the upper extremities.

Peripheral circulatory function is assessed from finger skin temperature and the results of the nail compression test on the finger. The nail compression test evaluates the recovery time of normal color after the nail is pressed strongly for $10 \mathrm{~s} \mathrm{(14).} \mathrm{Sensory} \mathrm{func-}$ tion is assessed from the pain threshold and the vibratory sense threshold. Pain threshold is measured

\footnotetext{
1 Department of Public Health, Ehime University School of Medicine, Shigenobu, Ehime, Japan.
}

Reprint requests to: Dr N Harada, Department of Public Health, Ehime University School of Medicine, Shigenobu, Ehime, 791-02 Japan. by means of weighted needles and determined by the weight applied on the finger, hand, and arm. Vibratory sense threshold is measured on the finger at 125 , 250 , or $63 \mathrm{~Hz}$ with a vibration sensimeter (AU-02, Rion $\mathrm{Co}, \mathrm{Ltd})$. Motor function is evaluated from measurements of grasping power, pinching power of the thumb and another finger, and tapping ability of the finger for $30 \mathrm{~s}$.

In the cold provocation test, initially, the method specified immersing a hand in $5^{\circ} \mathrm{C}$ water for $10 \mathrm{~min}$. However, since suffering during the test was severe, the use of $10^{\circ} \mathrm{C}$ water is becoming more prevalent.

The Japanese Ministry of Labour has designated the cold provocation test, pinching power test, and tapping ability test as secondary medical examinations. However, it was pointed out that the insidious functional disorders in the early stage are missed if the cold provocation test is not included in the primary medical examination (5).

If a medical doctor judges it to be necessary, other function tests, such as plethysmography, thermography and thermoesthesiometry may be performed during the examination.

\section{Role of the function tests in the diagnosis of the hand-arm vibration syndrome}

The clinical features of the hand-arm vibration syndrome are affected by such factors as vibration intensity, vibration frequency, exposure period, noise, cold, muscle tone, and work posture. Because the characteristics of these factors differ among different kinds of vibratory tools and work, the clinical features of 
the syndrome vary considerably. For estimating the clinical condition of patients properly, a careful checkup of many aspects of the whole body should be made and the results evaluated.

The method of diagnosing the hand-arm vibration syndrome in Japan consists of an interview on the history of vibration exposure and subjective symptoms and a physical examination, together with function tests of the upper extremities. The subjective symptoms and the physical examination are not confined to the hands and arms, but include the musculoskeletal system of the whole body, the autonomic nervous system, the central nervous system, the cochleovestibular system, etc. For example, in our medical examinations for the syndrome in workers in a zinc mine (11) and an iron foundry (3), 78 variables of subjective symptoms and 46 variables of the physical examination were checked along with 62 variables of the function tests.

Based on the fact that the prevalence rate of Raynaud's phenomenon not resulting from vibration exposure is less than $0.5 \%$ in the Japanese male population, the subjective symptom of Raynaud's phenomenon is regarded as important for the diagnosis of vibration syndrome. The findings of the function tests are also regarded as important for evaluating the severity of the disorders in peripheral circulatory function, sensory function, and motor function in the upper extremities, as such disorders are considered to represent the fundamental characteristics of the handarm vibration syndrome. In addition, subjective symptoms and the findings of the physical examination are evaluated for a systematic determination of the clinical features.

\section{Validity of the function tests}

\section{Subjects and the data submitted to analysis}

Using the 21 variables of the function tests, including a cold provocation with $10^{\circ} \mathrm{C}$ water, we investigated the efficiency of discrimination between 58 workers with vibration-induced white finger (VWF) and 40 referents.

The 21 variables were as follows. From the functional capacity motor tests, grasping power, pinching power of the thumb and middle finger, and tapping ability of the middle finger were selected. From the sensory tests, pain threshold and vibratory sense threshold of the middle finger at $125 \mathrm{~Hz}$ were selected. From the peripheral circulation tests, skin temperature of the third finger and the value of the nail compression test on the middle finger were selected.

Of the workers in the VWF group, 20 were operators of leg-type rock drills in a zinc mine, 18 were chipping-hammer operators in an iron foundry, and 20 were motorcycle mail carriers. The referents had worked in the same places without occupational exposure to vibration. They were all male. Furthermore,
24 workers in whom VWF occurred a few times a week in winter were selected from the VWF group (VWF-s group). The average ages were 43.2 (range 29-61) years for the VWF group, 42.6 (range 32-57) years for the VWF-s group, and 41.7 (range 31-56) years for the referents. The average years of exposure to vibration were 13.6 (range 2-26) for the VWF group and 13.7 (range 4-24) for the VWF-s group. Their clinical conditions and work conditions have been reported previously in detail $(4,5)$.

From the raw data of the function tests, the following findings were observed (5). In the VWF group, vibratory sense threshold and pain threshold showed a significantly lower capacity of sensory function than in the reference group. Skin temperature after the cold provocation and the nail compression test also showed a significantly lower capacity of peripheral circulatory function. Although tapping ability also showed a lower value, the difference did not have statistical significance. Grasping power and pinching power did not differ significantly either between the two groups. In the VWF-s group, the differences, in a comparison with the reference group, were increased and grasping power showed a lower value.

\section{Specificity and sensitivity of the function tests}

Table 1 shows the specificities and sensitivities of the 21 variables of the function tests. The criteria used in this table were rounded off to give the specificities of the reference group at nearly $95 \%$. When compared with the values before the hands were immersed in cold water, the sensitivities of the vibratory sense threshold, skin temperature, and the nail compression test were higher after immersion; that of pain threshold was not. Comparison of all the 21 variables in the VWF group showed that the sensitivities were highest for vibratory sense threshold after immersion $(60-70 \%$ ), followed by the nail compression test after immersion (about $55 \%$ ), pain threshold $(30-50 \%)$, and skin temperature after immersion $(20-25 \%)$. They were lowest for grasping power, pinching power, and tapping ability $(2-5 \%)$. These tendencies were also observed in the VWF-s group, and the sensitivities were, in addition, higher than those in the VWF group, with the exception of that of the vibratory sense threshold.

Because a large number of variables were used for the function tests, the probability becomes lower for each subject that no variable would show an abnormal result. In practice, the evaluation of a case with a few variables with abnormal results differs among medical doctors. For the theoretical investigation of this problem, the following analysis was done. With the use of the number of variables fulfilling the criterion for abnormality in table 1 , the specificities and sensitivities were calculated to discriminate the VWF and VWF-s groups from the reference group. If the subjects with four abnormal variables or more among the 21 variables were diagnosed as patients, it was recognized 
Table 1. Specificities and sensitivities of the 21 variables of the function tests. [R group = reference group, VWF group = group with vibration-induced white finger, VWF-s group $=$ workers selected from the VWF group because of a high occurrence of VWF (a few times a week in winter)]

\begin{tabular}{|c|c|c|c|c|}
\hline & \multirow[b]{2}{*}{$\begin{array}{l}\text { Criterion } \\
\text { for } \\
\text { abnormality }\end{array}$} & \multirow[b]{2}{*}{$\begin{array}{c}\text { Specificity } \\
\mathrm{R} \text { group } \\
(\mathrm{N}=40) \\
(\%)\end{array}$} & \multicolumn{2}{|c|}{ Sensitivity } \\
\hline & & & $\begin{array}{c}\text { VWF } \\
\text { group } \\
(N=58) \\
(\%)\end{array}$ & $\begin{array}{c}\text { VWF-s } \\
\text { group } \\
(\mathrm{N}=24) \\
(\%)\end{array}$ \\
\hline \multicolumn{5}{|c|}{ Grasping power } \\
\hline $\begin{array}{l}\text { Right } \\
\text { Left }\end{array}$ & $\begin{array}{l}<30 \mathrm{~kg} \\
<30 \mathrm{~kg}\end{array}$ & $\begin{array}{r}97.5 \\
100.0\end{array}$ & $\begin{array}{l}3.4 \\
1.7\end{array}$ & $\begin{array}{l}8.3 \\
4.2\end{array}$ \\
\hline \multicolumn{5}{|c|}{ Pinching power } \\
\hline $\begin{array}{l}\text { Right } \\
\text { Left }\end{array}$ & $\begin{array}{l}<3 \mathrm{~kg} \\
<3 \mathrm{~kg}\end{array}$ & $\begin{array}{r}95.0 \\
100.0\end{array}$ & $\begin{array}{l}1.7 \\
3.4\end{array}$ & $\begin{array}{l}4.2 \\
4.2\end{array}$ \\
\hline \multicolumn{5}{|c|}{ Tapping ability } \\
\hline $\begin{array}{l}\text { Right } \\
\text { Left }\end{array}$ & $\begin{array}{l}<110 \\
<100\end{array}$ & $\begin{array}{l}95.0 \\
95.0\end{array}$ & $\begin{array}{l}5.2 \\
3.4\end{array}$ & $\begin{array}{l}4.2 \\
8.3\end{array}$ \\
\hline \multicolumn{5}{|c|}{$\begin{array}{l}\text { Vibratory sense } \\
\text { thresholda }\end{array}$} \\
\hline $\begin{array}{l}\text { A } \\
B \\
C \\
\text { D }\end{array}$ & $\begin{array}{l}\geq 15 \mathrm{~dB} \\
\geq 30 \mathrm{~dB} \\
\geq 22.5 \mathrm{~dB} \\
\geq 20 \mathrm{~dB}\end{array}$ & $\begin{array}{l}95.0 \\
92.5 \\
95.0 \\
92.5\end{array}$ & $\begin{array}{l}34.5 \\
69.0 \\
65.6 \\
62.1\end{array}$ & $\begin{array}{l}29.2 \\
62.5 \\
70.8 \\
70.8\end{array}$ \\
\hline \multicolumn{5}{|c|}{ Pain thresholda } \\
\hline $\begin{array}{l}\text { A } \\
\text { B } \\
\text { C } \\
\text { D }\end{array}$ & $\begin{array}{l}\geq 10 \mathrm{~g} \\
>15 \mathrm{~g} \\
\geq 15 \mathrm{~g} \\
\geq 10 \mathrm{~g}\end{array}$ & $\begin{array}{l}90.0 \\
97.5 \\
92.5 \\
90.0\end{array}$ & $\begin{array}{l}41.4 \\
32.8 \\
32.8 \\
48.3\end{array}$ & $\begin{array}{l}54.2 \\
45.8 \\
50.0 \\
66.7\end{array}$ \\
\hline \multicolumn{5}{|c|}{ Skin temperature } \\
\hline $\begin{array}{l}\text { A } \\
\text { C } \\
D\end{array}$ & $\begin{array}{l}<25^{\circ} \mathrm{C} \\
<13.5^{\circ} \mathrm{C} \\
<15^{\circ} \mathrm{C}\end{array}$ & $\begin{array}{l}92.5 \\
95.0 \\
97.5\end{array}$ & $\begin{array}{l}13.8 \\
24.1 \\
22.4\end{array}$ & $\begin{array}{l}12.5 \\
37.5 \\
33.3\end{array}$ \\
\hline \multicolumn{5}{|c|}{$\begin{array}{l}\text { Nail compression } \\
\text { test }\end{array}$} \\
\hline $\begin{array}{l}\text { A } \\
\text { B } \\
\text { C } \\
\text { D }\end{array}$ & $\begin{array}{l}\geq 3 \mathrm{~s} \\
\geq 5 \mathrm{~s} \\
\geq 4.5 \mathrm{~s} \\
\geq 4 \mathrm{~s}\end{array}$ & $\begin{array}{l}87.5 \\
92.5 \\
92.5 \\
92.5\end{array}$ & $\begin{array}{l}29.3 \\
51.7 \\
56.9 \\
53.4\end{array}$ & $\begin{array}{l}29.2 \\
50.0 \\
66.7 \\
66.7\end{array}$ \\
\hline
\end{tabular}

a $=$ before immersion, $B=$ immediately after immersion, $C=$ five minutes after immersion, $\mathrm{D}=$ ten minutes after immersion [ie, immersion in cold $\left(10^{\circ} \mathrm{C}\right)$ water for $\left.10 \mathrm{~min}\right]$.

that the specificity in the reference group was $95 \%$ and the sensitivities in the VWF group and the VWF-s group were 77.6 and $87.5 \%$, respectively. These results confirmed that the function tests were of diagnostic significance for the hand-arm vibration syndrome.

\section{Several factors influencing the results of the function tests}

Age

Some studies were made on the influence of ageing on the function tests. The influence of ageing was evident for grasping power (12) and should be taken into consideration when the examination data of the subjects over 40 or 50 years of age are evaluated. The influence of ageing was also observed for vibratory sense threshold $(8,13)$, and it may be better to use age-corrected criteria for subjects over 50 years of age. For skin temperature and the nail compression test, the influence of ageing was not so evident at room temperature but was somewhat a factor after cold provocation $(9,13)$.

\section{Room temperature and season}

We studied the influence of atmospheric temperature in the test room and the seasonal variations on the circulatory and sensory tests $(2,6)$. The values of skin temperature and of the nail compression test and the vibratory sense threshold varied with a change of $2-3^{\circ} \mathrm{C}$ in the atmospheric temperature of the test room. Likewise, the values of skin temperature, the nail compression test, and the vibratory sense threshold measured in summer indicated better function than those determined in other seasons. In Japan, it has been recommended that the medical examination for the hand-arm vibration syndrome be performed in autumn or winter in an atmospheric temperature of $20-23{ }^{\circ} \mathrm{C}$ in the test room. We consider that such conditions should be used as standards.

\section{Reproducibility}

The reproducibility of the function tests was investigated, with the exception of that of the cold provocation test (7). The same subjects were examined twice at intervals of one year, and the values were compared. The correlation coefficients of grasping power, skin temperature, and the nail compression test were greater than that of the systolic blood pressure measured at the same time. The correlation coefficients of the vibratory sense threshold and pain threshold were more or less smaller than that of the systolic blood pressure. This observation indicates that the reliability of the function tests is within permissible levels.

\section{Standardization of the test method}

The equipment and techniques required for the function tests performed in Japan are basically standardized (10). The function tests are characteristic in that particular kinds of equipment or specialized techniques are not required, a number of people can be examined in a limited time, and physical discomfort to the subjects is not very great. A survey throughout the country showed that peripheral circulatory and sensory tests had been adopted in more than $90 \%$ of 35 institutes and hospitals which were diagnosing or treating patients with the hand-arm vibration syndrome, and motor tests of functional capacity had been adopted in approximately $50 \%$ (1).

Furthermore, these function tests have been utilized in some studies for the epidemiologic investigation of the hand-arm vibration syndrome. However, in these studies, the results of the function tests performed in one research institute were analyzed. For comparing and analyzing the results of the function tests performed in two or more research institutes, further investigation of the standardization of the test and evaluation methods is necessary. 


\section{References}

1. Committee on Vibration Hazards in the Japanese Association of Industrial Health. The publication of the committee work [in Japanese]. Japanese Association of Industrial Health, Tokyo, 1980.

2. Harada N, Hirosawa I, Fujii M, Dodo E. Seasonal variation of circulatory and sensory functions during immersion test in cold water for vibration syndrome [in Japanese]. Jpn J Ind Health 25 (1983) 422-431. (English abstract).

3. Harada N, Matsumoto T. Vibration disease in an iron foundry. In: Proceedings of ninth Asian conference of occupational disease, Seoul Oct 22-28, 1979. Seoul, 1979 , pp 253-257.

4. Harada N, Matsumoto T. A study of various function tests on the upper extremities for vibration syndrome. Am Ind Hyg Assoc J 42 (1981) 887-892.

5. Harada N, Matsumoto T. Validity of various function tests performed in Japan as a screening test for vibration syndrome. Int Arch Occup Environ Health 54 (1984) $283-293$.

6. Hirosawa I, Harada N, Dodo E, Fujii M. Cold immersion tests for vibration disease under various room temperatures [in Japanese]. Jpn J Ind Health 23 (1981) $799-800$.

7. Iwasaki S, Suzuki H. Evaluation of six screening items for the vibration syndrome [in Japanese]. Jpn J Ind Health 26 (1984) 477-482. (English abstract).

8. Kasamatsu T, Miyashita K, Shiomi S, Iwata H. The effect of aging on the peripheral functions in farmers and chain saw operators: Part 1. Age-related changes in pain and vibratory sense thresholds [in Japanese]. Jpn
J Ind Health 23 (1981) 127-133. (English abstract).

9. Kasamatsu T, Miyashita K, Shiomi S, Iwata H. The effect of aging on the peripheral functions in farmers and chain saw operators: Part 2. Age-related changes in skin temperature and hyperemia time after pressing the nail [in Japanese]. Jpn J Ind Health 23 (1981) 270-277. (English abstract).

10. Labour Standards Bureau, Japanese Ministry of Labour. New version of criteria for recognition as vibration hazards [in Japanese]. Jpn Med J 2689 (1975) 94-96.

11. Matsumoto $T$, Yamada S, Hisanaga N, Harada N, Kaneda K. On vibration hazards in rock-drill operators of a metal mine [in Japanese]. Jpn J Ind Health 19 (1977) 256-265. (English abstract).

12. Ochi H, Kamita N, Ohno H, Watanabe H, Kishihara C, Sugawara M, Muramatsu T, Homma H, Saito K, Takakuwa E. Studies on the items for diagnosis of the vibration disease: Part 1. Examination of healthy workers using vibratory tools [in Japanese]. Jpn $\mathbf{J}$ Ind Health 21 (1979) 539-545. (English abstract).

13. Saito $K$, Niioka T, Fujimoto $S$, Kumashiro M. Studies on the propriety of the items adopted for the special health examination of vibration hazards at present [in Japanese]. Jpn J Ind Health 22 (1980) 355-367. (English abstract).

14. Yamada S. Primary factors for the occurence of white waxy changes of the finger in vibration hazards with presentation of the nail press test [in Japanese]. Jpn J Ind Health 14 (1972) 529-541. (English abstract).

15. Yamada S. Prevention of the vibration hazards caused by chain-saw operation in Japan. Proceedings of VIII-th World Congress on the Prevention of Occupational Accidents and Disease, Bucharest May 17-21, 1977. Bucharest, 1977, pp 664-666. 